\title{
Visual Parameterization \\ of Vaganov-Shashkin Simulation Model and its Application in Dendroecological Research
}

\author{
Ivan I. Tychkov*, Irina N. Koiupchenko, \\ Victor A. Ilyin and Vladimir V. Shishov \\ Siberian Federal University \\ 79 Svobodny, Krasnoyarsk, 660041, Russia
}

Received 04.08.2015, received in revised form 26.09.2015, accepted 20.11.2015

\begin{abstract}
There are many different methods and tools for data analysis in dendrochronology. Modeling is one of them. One of the main issues in modeling is a choice of the main factors. Climatic data (temperature and precipitation) are the most common and affordable of them. Based on Vaganov-Shaskin model the new algorithm of visual parameterization of three-ring growth-VS-oscilloscope was developed. Algorithm was tested on different species of woody plants - Larix gmelini and Picea obovata. A new parameterization and analysis of modeling results help to evaluate conditions of area of growth of woody plants, based on dynamic of two climate variables: temperature and precipitation, without adding information about area of growth.
\end{abstract}

Keywords: VS-model, parameterization, VS-oscilloscope, Central Siberia, tree-ring width, climate signal, tree-ring growth rates, larch, spruce.

DOI: $10.17516 / 1997-1389-2015-8-4-478-494$.

(C) Siberian Federal University. All rights reserved

* Corresponding author E-mail address: ivan.tychkov@gmail.com 


\title{
Визуальная параметризация \\ имитационной модели Ваганова-Шашкина \\ и ее применение \\ в дендроэкологических исследованиях
}

\author{
И.И. Тычков, И.Н. Коюпченко, \\ В.А. Ильин, В.В. Шишов \\ Сибирский федеральный университет \\ Россия, 660041, Красноярск, пр. Свободный, 79
}

\begin{abstract}
В дендрохронологии используется большое количество различных аналитических подходов для анализа данных, одним из которых является моделирование. При создании любой модели одним из главных вопросов выступает выбор главных факторов. Самые распространенные и доступные климатические данные - температура и осадки.

На основании имитационной модели Ваганова-Шашкина предложен новый алгоритм визуальной параметризации роста годичных колеи хвойных деревьев, названный «VSосииллограф», и описана его программная реализация. Полученный алгоритм был апробирован на двух породах древесных растений-Larix gmelini и Picea obovata. Новый способ параметризации и анализ моделируемых результатов позволяют оценить локальные условия произрастания древесных растений на основе динамики двух климатических переменных: температуры и осадков, без привлечения дополнительной информации о местообитании.
\end{abstract}

Ключевые слова: VS-модель, параметризация, VS-осциллограф, Центральная Сибирь, ширина годичного кольиа, климатический сигнал, скорость роста годичных колец, лиственница, ель.

\section{Введение}

Одной из основных задач дендрохронологии служит изучение погодичной изменчивости качественных и количественных характеристик слоев прироста древесины и выявление факторов внешней среды, определяющих эту изменчивость (Мазепа, 1984; Ваганов и др., 1996; Ваганов, Шашкин, 2000; Shishov, 2000; Shishov et al., 2002, 2007).

Одним из полезных инструментов в решении данной задачи признано использование моделей роста деревьев.

Существует несколько типов моделей роста деревьев, различающихся между собой целями, методами и количеством рас- сматриваемых параметров или количеством исследуемых образцов. Например, модели, используемые для изучения групп деревьев, которые более или менее однородны относительно плотности, размера, среды обитания и вида (в английской литературе whole stand models). Такие параметры, как количество деревьев в исследуемой области, занимаемая площадь, помогают сделать прогноз о приросте и продуктивности древостоев (Vanclay, 1994). С другой стороны, также используются модели отдельного дерева, требующие информации о пространственном положении дерева или высоты деревьев и типа кроны, моделирующие структуру ветвей и характе- 
ристики внутренней части ствола (в английской литературе single-tree models) (Mitchell, 1988; Vanclay, 1988).

В целом модели можно разделить на два класса: модели для прогнозов прироста деревьев (models for predictions) и модели, описывающие процесс роста (process-based models) (Vanclay, 1994).

Модели прогноза прироста используются для эффективного выбора методов ведения лесного хозяйства. В таких моделях иногда опускается влияние некоторых факторов и конкретных деталей.

В противоположность им существуют имитационные модели - модели, описывающие процесс роста на основе климатических данных, солнечной радиации, влияния почвенных характеристик на рост деревьев. Такие модели полезны для понимания исследуемых процессов роста и нахождения новых закономерностей, отражающих взаимодействие факторов внешней среды с биологическими процессами, происходящими внутри исследуемых биологических объектов - древесных растений (Tolwinski-Ward et al., 2011; Guiot et al., 2014). Именно к этим моделям и относится имитационная модель прироста годичных колец древесных растений ВагановаШашкина (Ваганов, Шашкин, 2000; Vaganov et al., 2006; Anchukaitis et al., 2006; Evans et al., 2006; Touchan et al., 2012).

В данной работе предложен новый алгоритм визуализации и оптимизации имитационной модели Ваганова-Шашкина для выявления и анализа закономерностей в приросте древесных растений в связи с изменениями основных климатических факторов (температуры и осадков). Данная версия модели получила название VSосциллограф по аналогии с физическим прибором осциллографом. Напомним, осциллограф - прибор, предназначенный для исследования амплитудных и временных параметров электрических сигналов, подаваемых на дисплей. Было решено разработать виртуальный аналог данного физического прибора, предназначенный для моделирования древесно-кольцевых хронологий при помощи визуальной манипуляции значениями основных параметров VSмодели, позволяющей получать наилучшее приближение моделируемой кривой прироста. VS-осциллограф позволяет моделировать нелинейную реакцию роста деревьев на изменения климата, оценивая при этом вклад каждой климатической переменной в изменчивость сезонной динамики формирования годичных колец древесных растений (Тычков и др., 2012; Shishov et al., 2015).

\section{Описание модели}

\section{Ваганова-Шашкина}

Базовый алгоритм модели ВагановаШашкина можно разделить на следующие этапы (Ваганов, Шашкин, 2000):

- ввод климатических данных суточного разрешения;

- расчет интегральной скорости роста годичного кольца на основе входных климатических данных (Vaganov, Shashkin, 2000; Ивановский, Шишов, 2010);

- вычисление количества клеток, сформировавшихся за год, и их радиальных размеров на основе полученных данных по интегральной скорости роста (рис. 1).

Необходимыми входными параметрами модели являются среднесуточная температура, суточная сумма осадков и освещенность.

Для определения интегральной скорости роста $\mathrm{G}(\mathrm{t})$ используется соотношение

$$
G(t)=g_{E}(t) \cdot \min \left\{g_{T}(t), g_{W}(t)\right\},
$$




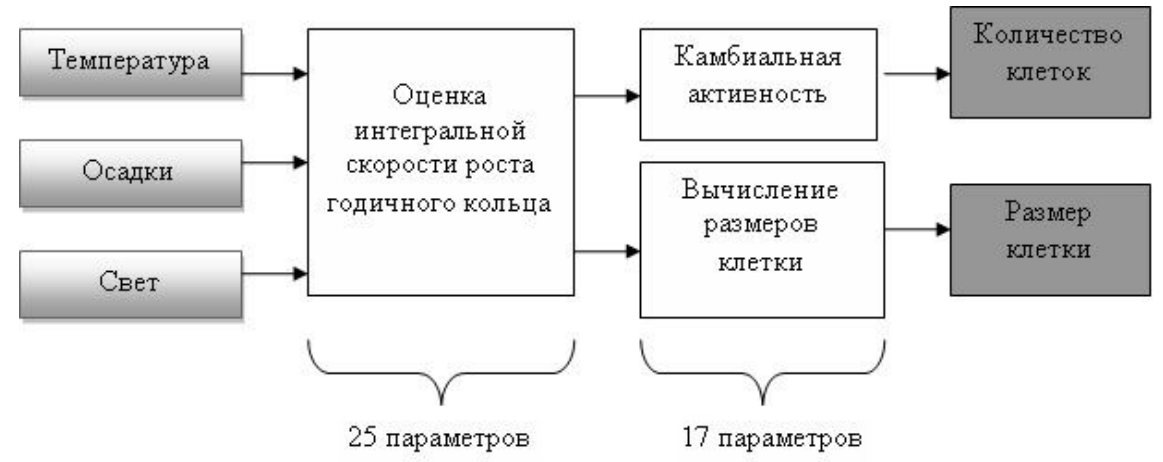

Рис. 1. Блок-схема алгоритма модели

где $\mathrm{G}(\mathrm{t})$ - интегральная скорость роста; $\mathrm{gE}(\mathrm{t})$, $\mathrm{gT}(\mathrm{t}), \mathrm{gW}(\mathrm{t})$ - частные скорости роста, зависящие от приходящей радиации $\mathrm{E}$, температуры T и содержания воды в почве $\mathrm{W}$.

Модель оценивает ежедневный водный баланс на основе данных о накопленных в почве осадках (с учетом или без таянья снега), испарении (которое зависит от температуры) и стоке (Thornthwaite, Mather, 1955). Количество приходящего солнечного света определяется моделью в зависимости от широты, на которой находится метеорологическая станция или дендрохронологический тестполигон (Ваганов, Шашкин, 2000; Vaganov et al., 2006).

Далее на основе полученных данных по интегральной скорости роста вычисляется количество клеток, сформировавшихся за год, и их размеры.

В блоке, описывающем изменения в скорости роста камбиальной зоны, процесс дифференциации клеток моделируется для одного среднего радиального ряда.

Скорость образования новых клеток зависит от количества клеток в камбиальной зоне и скорости их деления. Каждая клетка в камбиальной зоне определяется двумя характеристиками (Ваганов, Шашкин, 2000; Vaganov et al., 2006; Тычков и др., 2012):
- положением $j$ в радиальном ряду относительно начального значения;

- радиальным диаметром $D(j, t)$ в зависимости от положения $j$ и момента времени $t$.

Использование VS-осциллографа позволяет добавить еще один этап к базовому алгоритму модели Ваганова-Шашкина - подбор оптимальных параметров модели (см. ниже) для описания реального прироста.

\section{Описание VS-осциллографа}

VS-осциллограф является программным обеспечением с графическим пользовательским интерфейсом, созданным на базе компьютерного языка Lazarus - свободной среды разработки программного обеспечения, разработанной для и при поддержке компилятора Free Pascal. Данная среда программирования позволяет разрабатывать кросс-платформенное приложение, тем самым VS-модель можно использовать на компьютере независимо от установленной операционной системы (Windows, Linux и т.д).

В качестве тестовой модели использовалась модель Ваганова-Шашкина (VS-model), написанная на языке Fortran 5 (Vaganov et al., 2006).

Интерфейс блока управления VSосциллографа содержит две вкладки, отве- 

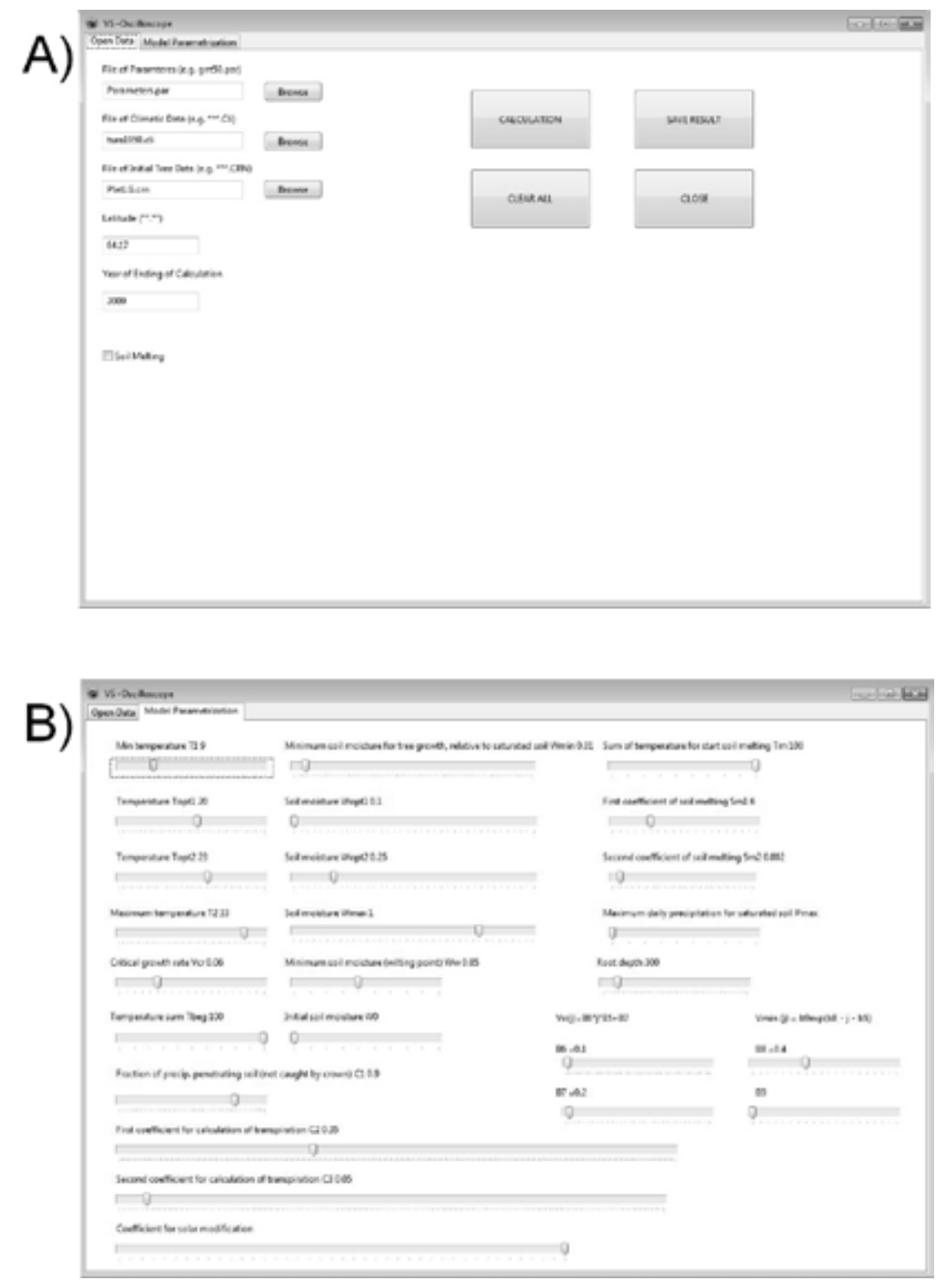

Рис. 2. Блок управления VS-осциллографа: вкладка «Данные» (А) и вкладка “Настройка параметров” (B)

чающие за ввод исходных данных (рис. 2А) и настройку параметров (рис. 2В). Исходные данные, содержащие суточные значения температур и накопленных осадков, а также значения исходной древесно-кольцевой хронологии, вводятся по определенному формату, описанному в разделе “Help". VSосциллограф оперирует 42 параметрами, описывающими условия обитания исследуемых древесных растений. Согласно алгоритму мо- дели Ваганова-Шашкина (рис. 1) параметры можно разделить на две группы: параметры, необходимые для вычисления интегральной скорости роста древесных колец, - 25 штук, и параметры, необходимые для определения камбиальной активности, - 17 штук. Значения 24 параметров можно изменять вручную на панели Model Parameterization, двигая индикаторы значений (в дальнейшем бегунки) вдоль значений шкал. Остальные параметры 
модели являются фиксированными и не меняют своих значений от условий произрастания древесных растений. По этой причине данные параметры не выводятся на панель.

Виртуальный дисплей представляет собой новое графическое окно с двумя графиками: красный - построенный на реальных данных (исходная древесно-кольцевая хронология), загруженных из файла *.crn; синий график, построенный на данных модели, вычисленных программой (рис. 3).

На первом этапе пользователь загружает все необходимые данные. Через кнопку Browse указывается путь и имя следующих файлов:

- файл с основными 42 параметрами (grrt50.par) в поле File of Parameters;

- файл с данными, необходимыми для вычисления камбиальной активности (CMB50.par), в поле File of Cambium Data;
- файл с данными для вычисления размеров клетки (CSC50.PAR) в поле File of Cell Size and Data for Calculation;

- файл с климатическими данными за год Name****.CLI (****-год, именно с указанного года начинаются вычисления) в поле File of Climatic Data;

- в поле Latitude указывается широта выбранного дендроклиматологического участка в формате “градусы.десятые_ градуса", например $70,62^{\circ}$ с. ш. (широта местоположения метереологической станции) будут заданы в модель как 70.62;

- в поле Year of Ending of Calculation указывается год окончания расчетов. Например, если нужно произвести вычисления с 1975 по 1989 г., необходимо выбрать файл с расширением. CLI и годом 1975 и в поле последнего

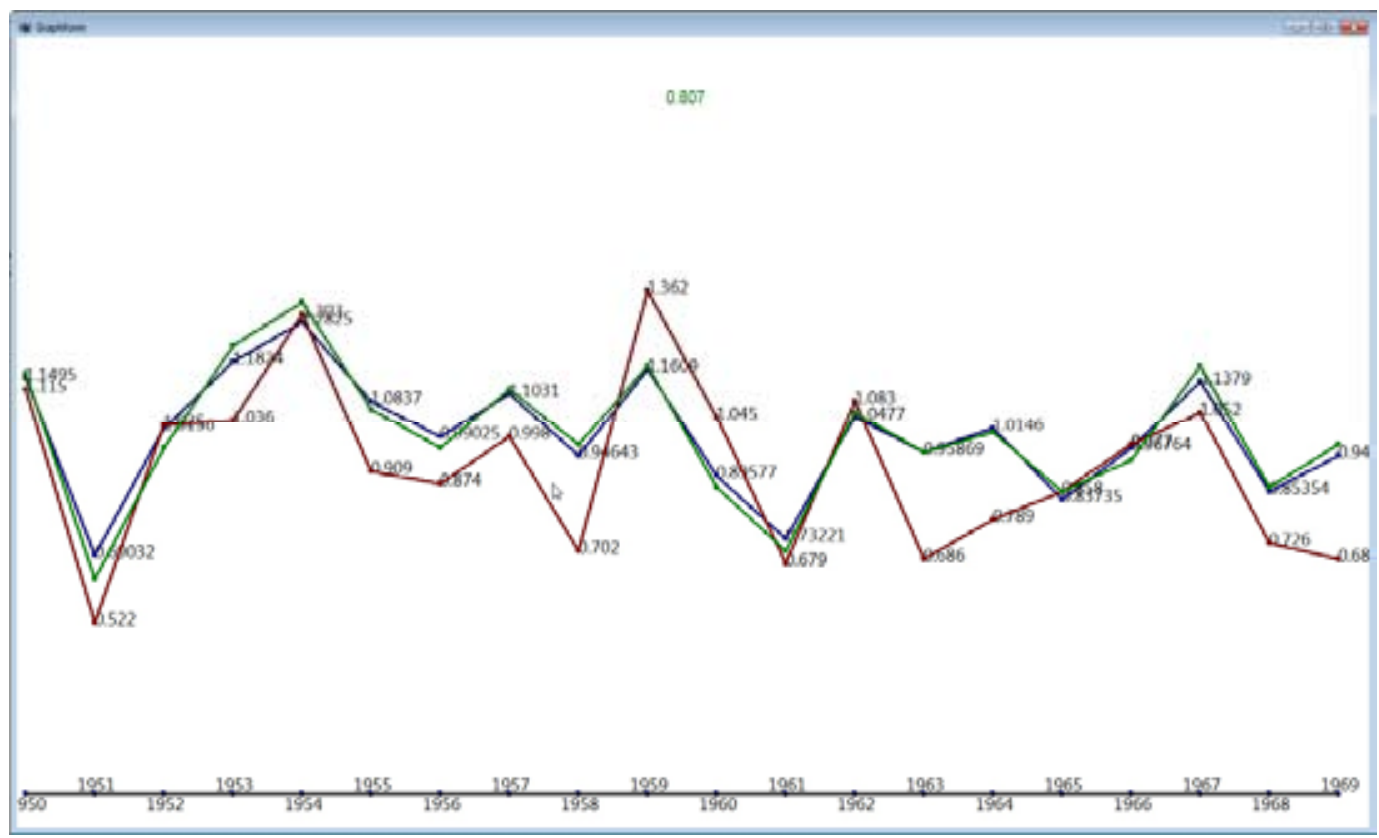

Рис. 3. Виртуальный дисплей VS-осциллографа с графиками исходной древесно-кольцевой хронологии (красная линия), моделируемой кривой роста, построенной на основе текущих параметров (синяя линия), моделируемой кривой роста, построенной на основе предыдущего набора параметров (зеленая линия) и коэффициентом корреляции между исходной и моделируемой хронологиями

$$
-483-
$$


года вычислений ввести 1989 (рис. 2А)

(Тычков и др., 2012).

После окончания работы программы полученные результаты сохраняются в новой папке Result - поддиректории папки с основным файлом параметров.

По завершении расчетов создаются несколько отдельных файлов с полученными результатами:

- файл хронологий (например, tura 19711977.dat) - в таблице представлены смоделированный индекс прироста (indc), исходные хронологии для исследуемого участка (crn), номер дня начала (BG1) и окончания сезона роста (EG1) для каждого года (рис. 4);

- файл скоростей (например, tura rate 1971-1977.dat) - в таблице первый столбец год Year, следующие - номер дня t, температура Tem $\left({ }^{\circ} \mathrm{C}\right)$, осадки Prec (мм), влажность почвы Sm, глубина оттаявшей почвы Dep (мм), толщина снежного покрова Snow (мм) (динамика не включена в данную версию программы), интегральная скорость роста $\mathrm{Gr}$, скорость в зависимости от влажности почвы Grw, скорость роста в зависимости от температуры GrT и величина суточной транспирации Solar (мм) (рис. 5);

- файл динамики камбиальной деятельности - год Year, время t (номер дня), число клеток камбиальной зоны $\mathrm{Nc}$ и общее число клеток в годичном кольце $\mathrm{Nr}$ (рис. 6);

- файл, содержащий информацию о размерах трахеид в годичном кольце, номер клетки i, радиальные размеры (мкм): измеренные $\mathrm{rd}$ и расчетные $\mathrm{cd}$ соответственно (рис. 7).

Изначально на панели Model Parameterization все бегунки для каждого па-

\begin{tabular}{|c|c|c|c|c|}
\hline \multicolumn{6}{|c|}{ Calculation from 1971 to 2005} \\
\hline Year & Model & CRN & BG1 & EG1 \\
\hline 1971 & 1,12 & 0,93 & 150 & 248 \\
\hline 1972 & 1,11 & 0,94 & 152 & 235 \\
\hline \multicolumn{5}{|c|}{} \\
\hline 1976 & 0,9 & 0,99 & 159 & 229 \\
\hline 1977 & 0,63 & 1,03 & 163 & 219 \\
\hline
\end{tabular}

Рис. 4. Результат работы модели, сохраненный в файл tura 1971-1977.dat

\begin{tabular}{|c|c|c|c|c|c|c|c|c|c|c|}
\hline Year & $\mathrm{t}$ & Tem & Prec & Sm & Dep & snow & Gr & Grw & GrT & Solar \\
\hline 1971 & 1 & $-31,38$ & 0 & 0,01 & 500 & 0 & 0 & 0 & 0 & 0,02 \\
\hline 1971 & 2 & $-32,6$ & 0 & 0,01 & 500 & 0 & 0 & 0 & 0 & 0,02 \\
\hline 1971 & 364 & $-40,14$ & 0 & 0,01 & 500 & 0 & 0 & 0 & 0 & 0,02 \\
\hline 1971 & 365 & $-34,48$ & 11 & 0,09 & 500 & 0 & 0 & 0 & 0 & 0,02 \\
\hline
\end{tabular}

Рис. 5. Результат работы модели, сохраненный в файл tura rate 1971-1977.dat 


\begin{tabular}{|c|c|c|c|}
\hline Year & $\mathrm{t}$ & $\mathrm{Nc}$ & $\mathrm{Nr}$ \\
\hline 1971 & 1,00 & 2 & 0 \\
\hline 1971 & 153,00 & 2 & 0 \\
\hline
\end{tabular}

Рис. 6. Результат работы модели, сохраненный в файл Tura c.dat

раметра имеют положение на шкале возможных значений, соответствующее значению данного параметра во входном файле параметров grrt50.par. Например, если в файле параметров Tmin минимальная температура для начала роста годичного кольца принимала значение $5{ }^{\circ} \mathrm{C}$, то соответствующий бегунок автоматически будет установлен на шкале в значении 5 (рис. 2В). Любое изменение положения бегунка приводит к автоматическому запуску программы и пересчету результатов с новыми - выставленными на бегунках - значениями. При этом на виртуальном дисплее VS-осциллографа автоматически отображается новая моделируемая кривая роста, выделенная синим цветом, а предыдущая версия данной кривой отображается зеленым. Для новой оценки синхронности между исходной древесно-кольцевой хронологией и модельной кривой используется коэффициент корреляции Пирсона, который пересчитывается автоматически после изменения значений любого параметра (рис. 3).

\section{Отличия}

\section{от Fortran-реализации}

В связи с разницей в подходах программирования в языках Fortran и Lazarus и используемыми типами данных в VS-осциллограф были внесены изменения и уточнения. Поэтому результаты конечных вычислений, полученных на основании различных реализаций алгоритма модели Ваганова-Шашкина, на

\begin{tabular}{|c|c|c|}
\hline $\mathrm{i}$ & $\mathrm{rd}$ & $\mathrm{cd}$ \\
\hline 1 & 47,60 & 47,60 \\
\hline 2 & 42,40 & 41,80 \\
\hline
\end{tabular}

Рис. 7. Результат работы модели, сохраненный в файл Tura s.dat

языках программирования Fortran и Lazarus могут различаться.

В частности, были внесены изменения в формулу расчета парциальной скорости роста от солнечной радиации. В исходной реализации для Fortran значение частной скорости роста, зависящей от солнечной радиации $\mathrm{grE}(\mathrm{t})$, корректно рассчитывалось только для средних широт. B VS-осциллографе частная скорость роста, зависящая от солнечной радиации, рассчитывается с использованием формулы (Liu, Jordan, 1960):

$E=\frac{24}{\pi} * r * I_{s c}(\cos L \cos \delta \sin \omega+\omega \sin L \sin \delta)$,

где $E$ - суточная инсоляция; $r$ - отношение интенсивности солнечного излучения при нормальном падении за пределами атмосферы планеты к солнечной постоянной; $I_{s c}-$ солнечная постоянная, 1,958 кал/см².мин; $L$ - широта, град.; $\delta$ - солнечное склонение, град.; $\omega-$ часовой угол, град.

В случае если активен блок оттаивания, то интегральная скорость роста по влажности будет модифицирована на основании следующей формулы:

$$
G r W(i) \_c o r r=G r W(i) * \frac{\operatorname{dep}(i)}{L r},
$$

где $G r W(i)$ - интегральная скорость по влажности; $L r$ - глубина залегания корней, $\operatorname{dep}(i)-$ 
глубина оттаявшего слоя почвы на і-й день (Vaganov et al., 2006).

Также было введено условие, что если в течение 15 дней температура будет меньше $0{ }^{\circ} \mathrm{C}$, то глубина оттаивания почвы приравнивается к нулю начиная с первого дня с отрицательной температурой. Такое изменение сделано из-за того, что неизвестно, с каким запаздыванием замерзает почва в силу отсутствия характеристик теплопроводности почвы и длительных натурных наблюдений за процессом оттаивания почвы с большинства местообитаний древесных растений, имеющихся в Урало-Сибирском дендрохронологическом банке данных.

Эта проблема требует организации многолетних натурных экспериментов для различных условий местообитаний древесных растений в различных частях Евразии.

\section{Результаты и их обсуждение}

Апробация VS-осциллографа проводилась на дендроклиматических данных различных регионов Сибири, Центральной Азии и Средиземноморья. Для всех регионов получены параметры, обеспечивающие высокозначимую положительную корреляцию между исходными данными и модельными результатами.

В данной работе алгоритм параметризации апробирован для одного дендрохронологического тест-полигона, расположенного на территории среднего течения р. Енисей (пос. Тура) (64.17 с.ш., $110.13^{\circ}$ в.д.). Использованы данные двух участков с разными породами деревьев - PlatLG (вид древесных растений - лиственница Гмелина (Larix gmelini)) и PlatPO (ель сибирская (Picea obovata)).

Нами были использованы древеснокольцевые хронологии за период инструментальных климатических измерений суточного разрешения метеостанции пос. Тура с 1950 по 2009 г. Временной период наблюдений был разбит на период калибровки (1970-2009 гг.) и период верификации (1950-1969 гг.). На периоде калибровки подбирались параметры, при которых будет получена наибольшая положительная значимая корреляция между исходными древесно-кольцевыми хронологиями и моделируемыми кривыми прироста древесных растений. На периоде верификации проверялась прогностическая способность имитационной модели описать реальный прирост древесных растений на основании изменчивости ведущих климатических факторов с использованием ранее найденных параметров модели на этапе калибровки.

На участке PlatLG были получены следующие коэффициенты корреляции: $\mathrm{r}=0,71$ на периоде калибровки, $r=0,73$ на периоде верификации и $\mathrm{r}=0,72$ на всем рассматриваемом периоде (рис. 8). Средняя продолжительность сезона роста составила 95 дней $( \pm 15$ дней стандартная ошибка), с 147-го дня (27 мая) по 243-й (31 августа) (рис. 9). На протяжении всего сезона роста интегральная скорость по влажности GrW превышает интегральную скорость по температуре GrT, следовательно, лимитирующим фактором сезона роста является температура (рис. 10).

Для участка PlatPO были получены следующие коэффициенты корреляции: $\mathrm{r}=0,70$ на периоде калибровки, $\mathrm{r}=0,67$ на периоде верификации и $\mathrm{r}=0,70$ на всем рассматриваемом периоде (рис. 11). Средняя продолжительность сезона роста составила 94 дня ( \pm 13 дней), начиная с 151-го по 245-й день (31 мая - 2 сентября) (рис. 12). Первые дни сезона рост лимитируется влажностью, но с середины июня и до окончания сезона роста лимитирующим фактором становится температура (рис. 13).

Если сравнить параметры модели, для которых получены результаты (табл. 1), то 


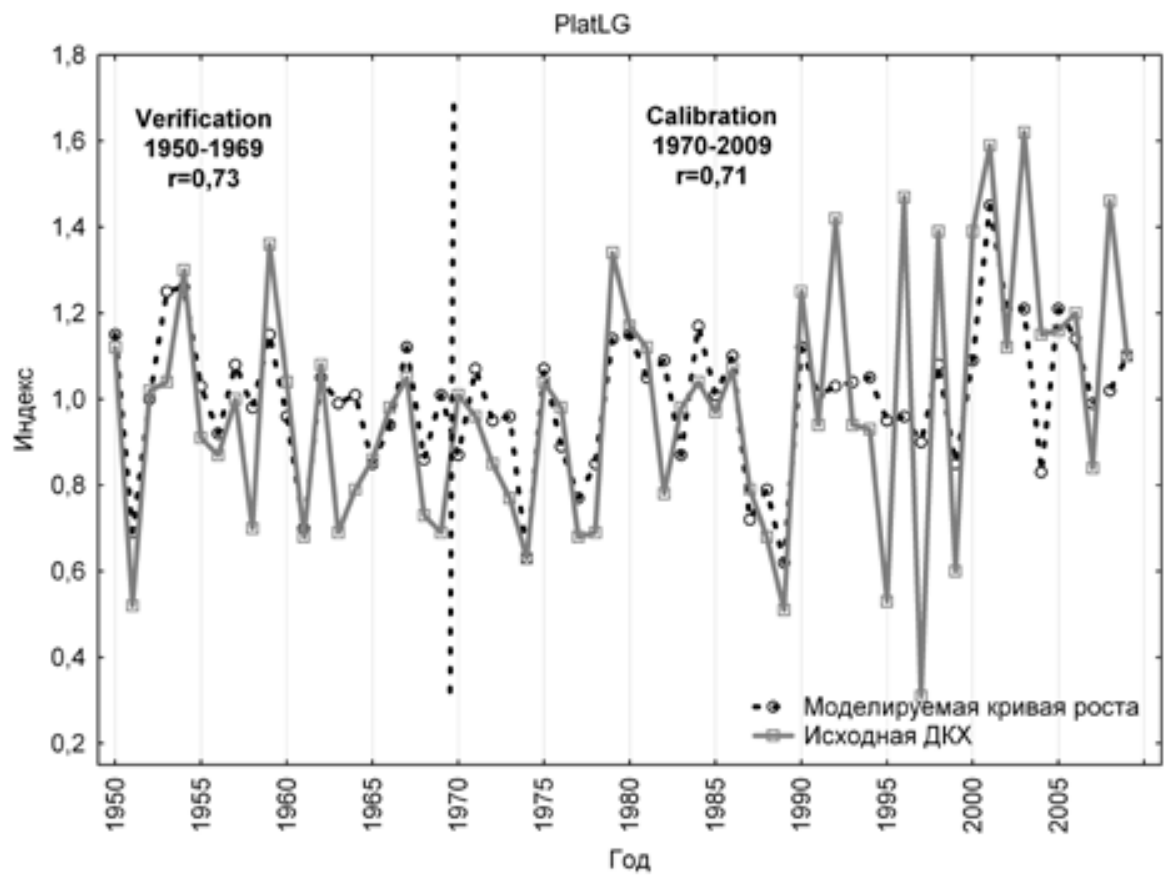

Рис. 8. Исходная древесно-кольцевая хронология (ДКХ), построенная по лиственнице Гмелина (сплошная линия), и динамика моделируемого прироста (пунктирная линия) для двух периодов: калибровки модели и верификации

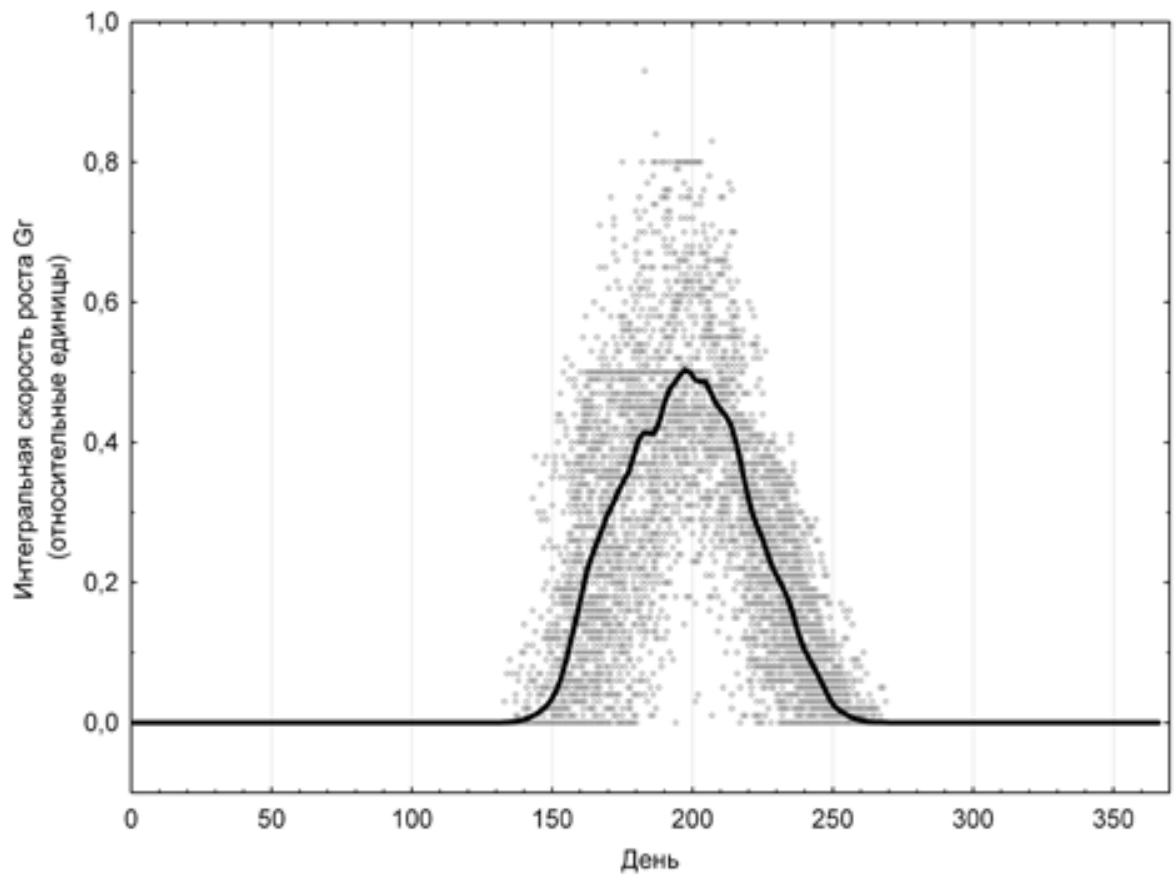

Рис. 9. Динамика интегральной скорости роста (Gr) в течение года (линия), полученная для лиственницы Гмелина. Точками отмечены ежедневные значения интегральной скорости роста $(\operatorname{Gr}(\mathrm{t}))$ 


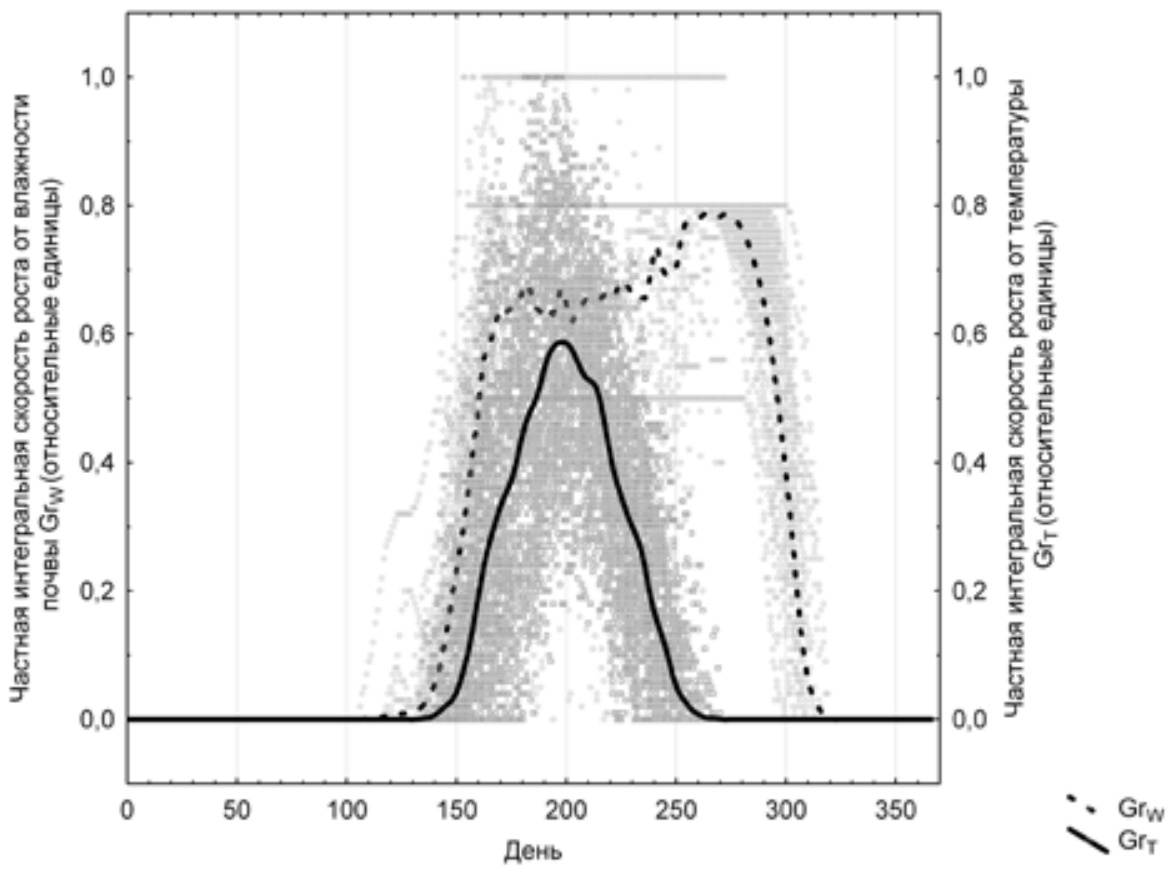

Рис. 10. Динамика парциальной скорости роста от влажности ( $\mathrm{Gr}_{\mathrm{W}}$, пунктирная линия) и парциальной скорости роста от температуры (Gr

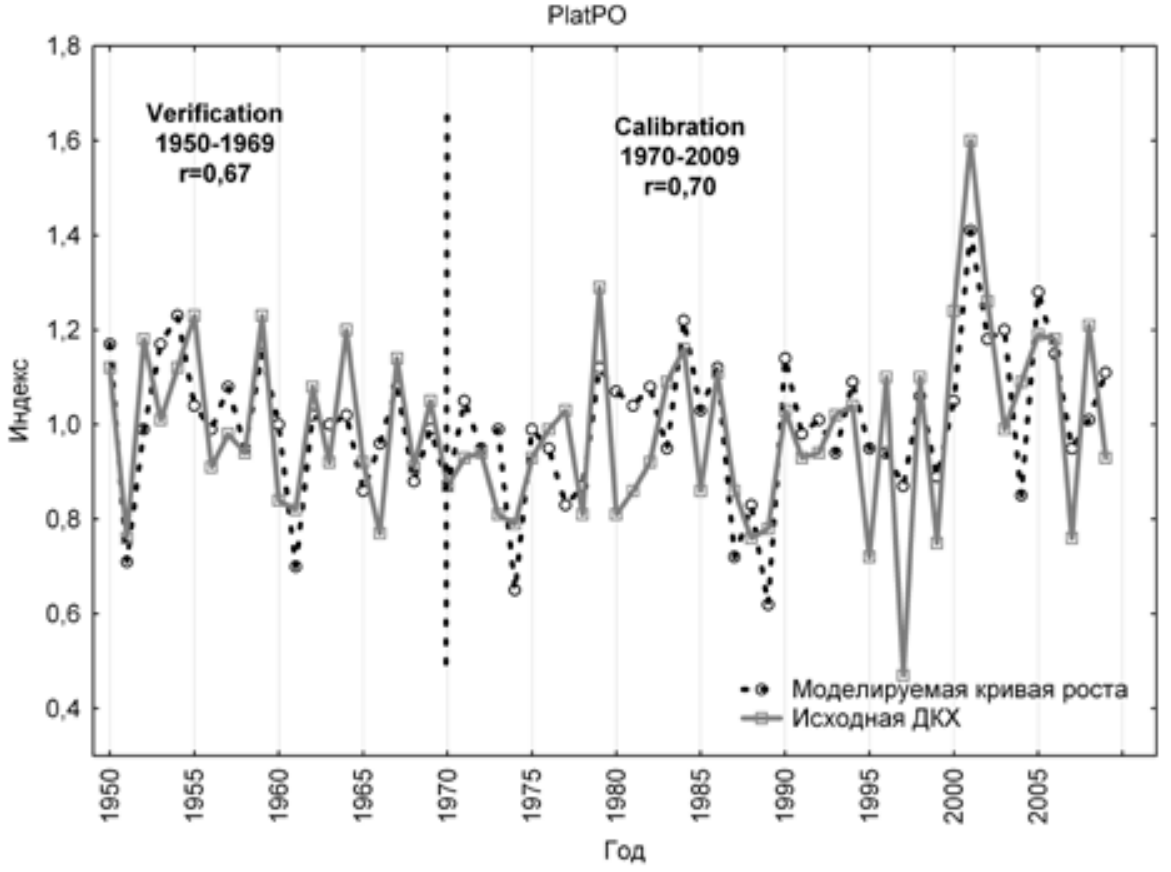

Рис. 11. Исходная древесно-кольцевая хронология (ДКХ), построенная по ели сибирской (сплошная линия), и динамика моделируемого прироста (пунктирная линия) для двух периодов: калибровки модели и верификации 


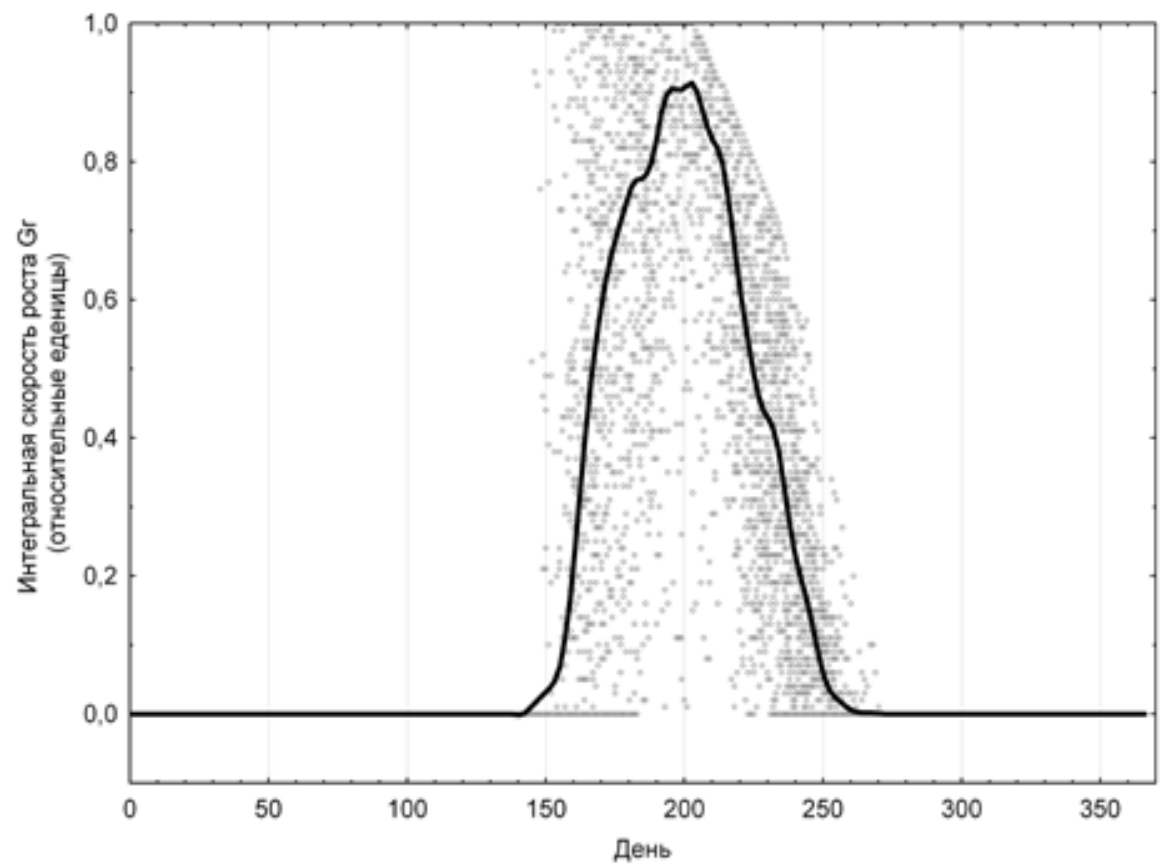

Рис. 12. Динамика интегральной скорости роста $(\mathrm{Gr})$ в течение года (линия), полученная для ели сибирской. Точками отмечены ежедневные значения интегральной скорости роста $(\operatorname{Gr}(\mathrm{t}))$

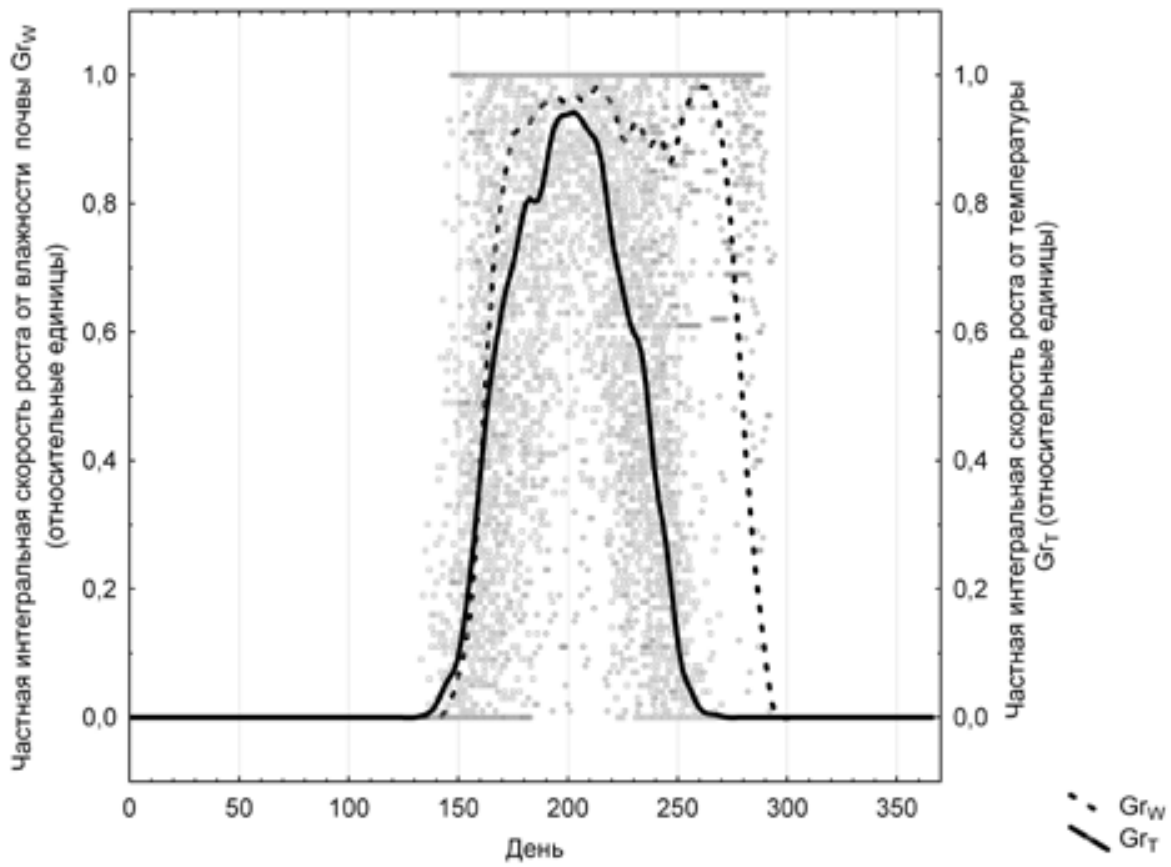

Рис. 13. Динамика парциальной скорости роста от влажности $\mathrm{Gr}_{\mathrm{w}}$ (пунктирная линия) и парциальной скорости роста от температуры $\mathrm{Gr}_{\mathrm{T}}$ (сплошная линия), полученная для ели сибирской 
Таблица 1. Параметры модели, при которых были получены результаты для лиственницы Гмелина (PlatLG) и ели сибирской (PlatPO) (курсивом выделены параметры, которые были заданы изначально и не изменяются пользователем)

\begin{tabular}{|c|c|c|c|}
\hline Параметр & Описание & PlatLG & PlatPO \\
\hline Tmin & Минимальная температура для начала роста $\left({ }^{\circ} \mathrm{C}\right)$ & 8 & 8 \\
\hline Topt 1 & $\begin{array}{l}\text { Нижняя граница температуры, при которой интегральная } \\
\text { скорость роста достигает максимума }\left({ }^{\circ} \mathrm{C}\right)\end{array}$ & 24 & 16 \\
\hline Topt 2 & $\begin{array}{l}\text { Верхняя граница температуры, при которой интегральная } \\
\text { скорость роста достигает максимума }\left({ }^{\circ} \mathrm{C}\right)\end{array}$ & 26 & 27 \\
\hline Tmax & Максимальная температура, при которой возможен рост $\left({ }^{\circ} \mathrm{C}\right)$ & 31 & 31 \\
\hline Wmin & Минимальная относительная влажность почвы & 0,04 & 0,09 \\
\hline Wopt 1 & $\begin{array}{l}\text { Нижняя граница относительной влажности почвы, при которой } \\
\text { интегральная скорость роста достигает максимума }\end{array}$ & 0,1 & 0,1 \\
\hline Wopt 2 & $\begin{array}{l}\text { Верхняя граница относительной влажности почвы, при которой } \\
\text { интегральная скорость роста достигает максимума }\end{array}$ & 0,60 & 0,35 \\
\hline Wmax & Максимальная относительная влажность почвы & 1,000 & 0,825 \\
\hline$W 0$ & Начальная относительная влажность почвы & 0,09 & 0,09 \\
\hline Ww & $\begin{array}{l}\text { Минимальная относительная влажность почвы, при которой } \\
\text { начинается завядание }\end{array}$ & 0,07 & 0,10 \\
\hline Tbeg & Суммарная температура для начала сезона роста $\left({ }^{\circ} \mathrm{C}\right)$ & 100 & 100 \\
\hline tbeg & $\begin{array}{l}\text { Количество дней, необходимое для наступления суммарной } \\
\text { температуры (сут) }\end{array}$ & 10 & 10 \\
\hline lr & Глубина залегания корней (мм) & 500 & 500 \\
\hline$P \max$ & $\begin{array}{l}\text { Максимальное суточное количество осадков для достижения } \\
\text { насыщения грунта (мм/день) }\end{array}$ & 40 & 40 \\
\hline $\mathrm{C} 1$ & $\begin{array}{l}\text { Количество осадков, проникших в почву (не остановленных } \\
\text { кроной) (отн. ед.) }\end{array}$ & 0,85 & 0,50 \\
\hline $\mathrm{C} 2$ & Первый коэффициент для вычисления транспирации (мм/день) & 1,35 & 1,00 \\
\hline C3 & Второй коэффициент для вычисления транспирации (мм/день) & 0,01 & 0,01 \\
\hline Л & Коэффициент дренажа воды из почвы (отн. ед.) & 0,00 & 0,00 \\
\hline Tc & Временной шаг камбиальной модели (день) & 1,00 & 1,00 \\
\hline Vcr & Минимальная скорость роста камбиальной клетки (мкм/день) & 0,12 & 0,07 \\
\hline$D 0$ & Начальные размеры клетки (мкм) & 4,000 & 4,000 \\
\hline Dcr & Размер клетки на момент начала митотического цикла (мкм) & 8,000 & 8,000 \\
\hline $\mathrm{Vm}$ & Скорость роста в течение митотического цикла (мкм/день) & 1,000 & 1,000 \\
\hline $\mathrm{Dm}$ & Размер камбиальной клетки, при котором начинается митоз (мкм) & 10,00 & 10,00 \\
\hline Sm1 & Первый коэффициент оттаивания почвы $\left(\right.$ мм $\left./{ }^{\circ} \mathrm{C}\right)$ & 3 & 18 \\
\hline $\mathrm{Sm} 2$ & Второй коэффициент оттаивания почвы (ед/день) & 0,001 & 0,001 \\
\hline
\end{tabular}

можно увидеть существенную разницу между значениями параметров модели, отвечающих за температурные условия местообитания и влажность почвы (Topt1, Topt2, Wmin, C1) для двух разных пород, находящихся в одних климатических условиях.
Для двух различных видов деревьев разница в параметрах, отвечающих за нижнюю и верхнюю границы температуры, при которой скорость достигает максимума (Topt1 и Topt 2 , соответственно) - 24 и $26^{\circ} \mathrm{C}$ для лиственницы Гмелина (PlatLG) и 16 и $27{ }^{\circ} \mathrm{C}$ 
для ели сибирской (PlatPO), - является существенной (табл. 1). Это означает, что скорость роста лиственницы в начале сезона роста древесных растений существенно выше, чем скорость роста ели сибирской в примерно одних и тех же условиях местообитания. Это хорошо согласуется данными о большой чувствительности лиственницы Гмелина к температурным условиям (Kujansuu et al., 2007).

Другой результат, подтверждающий преимущество использования нового способа параметризации, заключается в следующем. Хорошо известно, что ель по сравнению с лиственницей выбирает, как правило, локально более увлажненные местообитания. Анализ значений минимальной относительной влажности почвы Wmin показывает, что для начала сезона роста ели необходима влажность почвы в два раза выше, чем для лиственницы (0,09 против 0,04$)$, что подтверждают натурные наблюдения.

Значения параметра $\mathrm{Cl}$, отвечающего за количество осадков, проникших в почву (не остановленных кроной дерева), 0,85 для лиственницы против 0,5 для ели объясняют возможности кроны разных видов деревьев задерживать влагу. В данном случае способность ели задерживать влагу выше, что также подтверждают многолетние натурные наблюдения.

Результаты применения нового способа параметризации модели Ваганова-Шашкина также хорошо соотносятся с результатами натурных наблюдений за оттаиванием почвы для хвойных древостоев разных пород в условиях вечной мерзлоты (Николаев 2008, 2008а). Известно, что в еловых древостоях это оттаивание происходит существенно медленней, чем в лиственничниках. Этот результат частично подтверждает модельные эксперименты при помощи VS- осциллографа. Можно отметить, что процесс оттаивания для лиственничного местообитания начинается раньше и идет более интенсивно (рис. 14), хотя статистический анализ не обнаружил значимых различий между кривыми. Это, скорее всего, объясняется тем, что при использовании блока оценки глубины оттаявшей почвы опускается ряд различных почвенных характеристик (например, теплопроводность, состав и др.), которые, безусловно, задействованы в этом процессе. Для решения этой проблемы необходимы многолетние наблюдения и сбор информации о характеристиках почвы и натурных наблюдений по глубине сезонного оттаивания. Возможно, для дальнейшего усовершенствования VS-осциллографа следует модифицировать блок оттаивания с использованием других алгоритмов его реализации (например, Tolwinski-Ward et al., 2011).

VS-осциллограф позволяет, не имея представлений о процессах роста тех или иных видов древесных растений, как получить первичную качественную информацию о процессах роста самих древесных растений, так и оценить условия произрастания древесных растений на основании использования только данных суточного разрешения по температуре воздуха и осадкам близлежащей метеостанции. В частности, выявить различия в реакции древесных растений разных пород на меняющиеся условия внешней среды, получить фенологические характеристики того или иного вида деревьев, оценить локальные условия местообитания и т.д.

\section{Заключение}

Работоспособность имитационной модели Ваганова-Шашкина ранее проверялась на обширном материале в Северном полушарии (см., например, Evans et al., 2006; Anchukaitis 


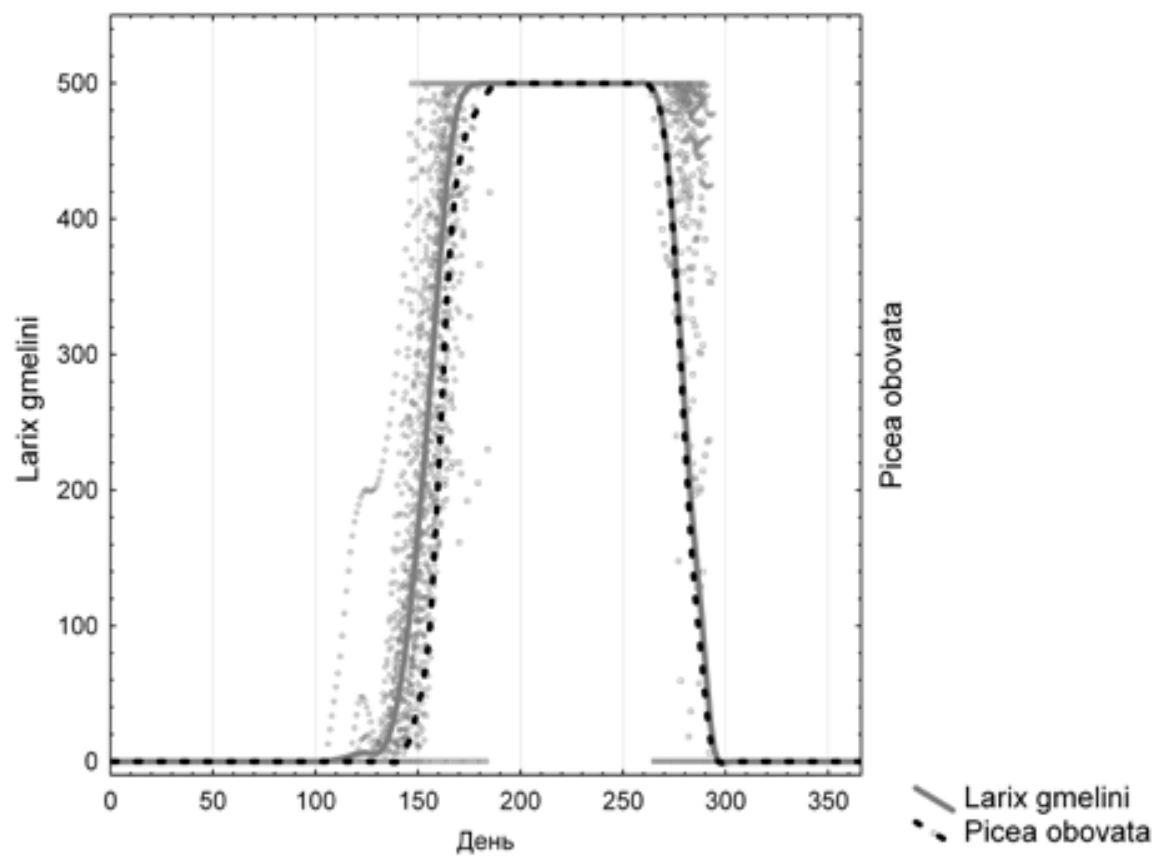

Рис. 14. Динамика глубины оттаивания почвы для Larix gmelini (сплошная линия) и Picea obovata (пунктирная линия)

et al., 2006). При этом параметризация модели не осуществлялась, набор параметров фиксировался для всех местообитаний. Новый способ визуальной параметризации, предложенный в данной статье, показал, что точная настройка модели позволяет получать качественно новые результаты, интерпретация которых улучшает понимание процессов роста древесных растений.

На основании полученных результатов можно сделать следующие выводы:

- разработан новый алгоритм визуальной параметризации (VS-осциллограф) имитационной модели ВагановаШашкина роста годичных колец хвойных растений;
- разработано программное обеспечение VS-осциллографа, реализующее данный способ параметризации;

- работа ПО VS-осциллограф апробирована для среднего течения р. Енисей для двух различных видов хвойных деревьев;

- показано хорошее совпадение модельных результатов с опубликованными натурными наблюдениями.

В дальнейших исследованиях для усовершенствования работы VS-осциллографа планируется использовать многолетние натурные наблюдения за камбиальной активностью и клеточной продукцией хвойных деревьев в различных условиях местообитаний.

Работа была поддержана грантом Российского научного фонда (проект № 14-14-00219). Авторский коллектив благодарит А.В. Кирдянова за предоставленные данные. 


\section{Список литературы}

Ваганов Е.А., Шашкин А.В. (2000) Рост и структура годичных колец. Новосибирск, Наука, 232 c. [Vaganov E.A., Shashkin A.V. (2000) The growth and structure of annual rings. Novosibirsk, Nauka, 232 p. (in Russian)]

Ваганов Е.А., Шиятов С.Г., Мазепа В.С. (1996) Дендроклиматические исследования в Урало-Сибирской Субарктике. Новосибирск, Наука, 246 с. [Vaganov E.A., Shiiatov S.G., Mazepa V.S. (1996) Dendroclimatic research in the Ural-Siberian Subarctic Zone. Novosibirsk, Nauka, 246 p. (in Russian)]

Ивановский А.Б., Шишов В.В. (2010) Алгоритм параметризации для модели ВагановаШашкина формирования годичных колец древесных растений. Вестн. СибГАУ, 2 (28): 83-88. [Ivanovskii A.B., Shishov V.V. (2010) The parameterization algorithm for the Vaganov-Shashkin model of annual rings formation of woody plants. Bulletin of SibSAU [Vestnik SibGAU], 2 (28): 83-88 (in Russian)]

Мазепа В.С. (1984) Математико-статистические модели дендрохронологических рядов: Дис. ... канд. физ.-мат. наук. Свердловск, 162 с. [Mazepa V.S. (1984) Mathematical and statistical models of dendrochronological series: $\mathrm{PhD}$ thesis in Physics and Mathematics. Sverdlovsk, 162 p. (in Russian)]

Николаев А.Н. (2008) Дендрохронологические исследования радиального прироста лиственницы в Якутии. Фундаментальные и прикладные проблемы ботаники в начале ХХІ века: материалы Всерос. конф. (Петрозаводск, 22-27 сент. 2008 г.). Ч. 5. Геоботаника. Петрозаводск, c. 236-239 [Nikolaev A.N. (2008) Dendrochronological research of the larch radial growth in Yakutia. Fundamental and applied problems of Botany at the beginning of the 21st century: Proceedings of the All-Russian Conference (Petrozavodsk, September 22-27, 2008). Part 5. Geobotany. Petrozavodsk, p. 236-239 (in Russian)]

Николаев А.Н. (2008а) Особенности роста древесных пород [лиственницы и сосны] Центральной Якутии в условиях многолетней мерзлоты. Чтения памяти А.П. Хохрякова: материалы Всерос. науч. конф. (Магадан, 28-29 окт. 2008 г.). Магадан, с. 150-154. [Nikolaev A.N. (2008a) Features of growth of woody species [larch and pine] in Central Yakutia in permafrost conditions. Readings in memory of A.P. Khokhriakov: Proceedings of the All-Russian Scientific Conference (Magadan, October28-29, 2008). Magadan, p. 150-154 (in Russian)]

Тычков И.И., Леонтьев А.С., Шишов В.В. (2012) Новый алгоритм параметризации модели роста годичных колец деревьев: VS-осциллограф и его применение в дендроэкологии. Системы. Методы. Технологии, 4 (16): 45-51. [Tychkov I.I., Leont'ev A.S., Shishov V.V. (2012) A new parameterization algorithm for the model of growth of annual tree rings: VS-oscilloscope and its application in dendroecology. Systems. Methods. Technologies [Sistemy. Metody. Tekhnologii], 4 (16): 45-51 (in Russian)]

Шишов В.В., Ваганов Е.А., Хьюз М.К., Корец М.А. (2002) Пространственная изменчивость прироста древесных растений на территории Сибири в последнем столетии. ДАН, 387: 690-693. [Shishov V.V., Vaganov E.A., Hughes M.K., Korets M.A. (2002) The spatial variability of the growth of woody plants in Siberia in the last century. DAN, 387: 690-693 (in Russian)]

Шишов В.В., Наурзбаев М.М., Ваганов Е.А., Ивановский А.Б., Корец М.А. (2007) Анализ изменчивости радиального прироста древесных растений на территории северной части Евра- 
зии в последние десятилетия. Известия Российской академии наук. Серия географическая, 3: 49-58. [Shishov V.V., Naurzbaev M.M., Vaganov E.A., Ivanovskii A.B., Korets M.A. (2007) Analysis of variability of the radial growth of woody plants in the territory of the northern part of Eurasia in recent decades. Proceedings of the Russian Academy of Sciences. Geographical Series [Izvestiia RAN. Geografiia], 3: 49-58 (in Russian)]

Шишов В.В. (2000) Статистические взаимосвязи между интенсивностью Эль-Ниньо и летними температурами в субарктическом регионе Сибири. ДАН, 375 (5): 676-679 [Shishov, V.V. (2000) Statistical relations between the intensity of El Niño and summer temperatures in the subArctic region of Siberia. DAN, 375 (5): 676-679 (in Russian)]

Anchukaitis K.J., Evans M.N., Kaplan A., Vaganov E.A., Hughes M.K., Grissino-Mayer H.D. and Cane M.A. (2006) Forward modeling of regional scale tree-ring patterns in the southeastern United States and the recent influence of summer drought. Geophysical Research Letters, 33: L04705.

Evans M.N., Reichert K., Kaplan A., Anchukaitis K.J., Vaganov E.A., Hughes M.K., Cane M.A. (2006) A forward modeling approach to paleoclimatic interpretation of tree-ring data. Journal of Geophysical Research, 111: G03008. DOI:10.1029/2006JG000166, 2006.

Guiot J., Boucher E., Gea-Izquierdo G. (2014) Process models and model-data fusion in dendroecology. Frontiers in Ecology and Evolution. Paleoecology, 2: Article 52.

Kujansuu J., Yasue K., Koike T., Abaimov A.P., Kajimoto T.T., Takeda Tokumoto M., Matsuura Y. (2007) Responses of ring widths and maximum densities of Larix gmelinii to climate on contrasting north- and south-facing slopes in central Siberia. Ecological Research, 22: 582-592.

Liu B.Y.H., Jordan R.C. (1960) Interrelationship and characteristic distribution of direct, diffuse and total solar radiation. Solar Energy, 4: 1-19.

Mitchell K.J. (1988) SYLVER: Modelling the impact of silviculture on yield, lumber value, and economic return. For. Chron., 64:127-131.

Shishov V.V., Tychkov I.I., Popkova M.I., Ilyin V.I., Bryukhanova M.V., Kirdyanov A.V. (2015) VS-oscilloscope: A new tool to parameterize tree radial growth based on climateconditions. Dendrochronologia. DOI: 10.1016/j.dendro.2015.10.001.

Touchan R., Shishov V.V., Meko D.M., Nouiri I., Grachev A. (2012). Process based model sheds light on climate signal of Mediterranean tree-ring width. Biogeosceinces, 9: 965-972. DOI:10.5194/ bg-9-965-2012.

Thornthwaite C.W., Mather J.R. (1955) The water balance. Publications in climatology. Vol. 1. Drexel Institute of Technology, Philadelphia, p 1-104.

Tolwinski-Ward S.E., Evans M.N., Hughes M.K., Anchukaitis K.J. (2011) An efficient forward model of the climate controls on interannual variation in tree-ring width. Climate Dynamics, 36 (1112): 2419-2439.

Vaganov E.A., Hughes M.K., Shashkin A.V. (2006) Growth dynamics of conifer tree rings: images of past and future environmens. Berlin, Heidelberg, Springer-Verlag, $343 \mathrm{p}$.

Vanclay J.K. (1994) Modelling forest growth and yield: applications to mixed tropical forests. Wallingford, UK, CAB International, 330 p.

Vanclay J.K., Henry N.B. (1988) Assessing site productivity of indigenous cypress pine forest in southern Queensland. Commonw. For. Rev., 67: 53-64. 